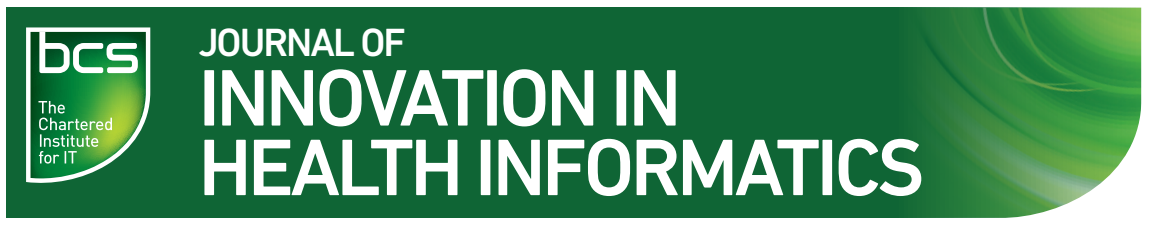

\title{
Editorial
}

Copyright $\odot 2018$ The Author(s). Published by BCS, The Chartered Institute for IT under Creative Commons license http://creativecommons.org/ licenses/by/4.0/

\section{Computerised medical record systems that guide and protect - reflections on the Bawa-Garba case}

\author{
Simon de Lusignan \\ Professor, Primary Care and Clinical Informatics, University of Surrey, UK \\ Editor-in-Chief Journal of Innovation in Health Informatics

\section{Harshana Liyanage} \\ Research Fellow, University of Surrey, UK

\section{Philip Scott} \\ Senior Lecturer \\ Deputy Editor Journal of Innovation in Health Informatics, Information Systems, University of Portsmouth, UK
}

\section{ABSTRACT}

Lawrence Weed proposed we develop computerised, problem-oriented medical records that guide and teach. The Bawa-Garba case outcomes might have been different if care had been supported by computerised medical record (CMR) systems. CMR systems can reduce prescribing errors and could be developed to flag gaps in supervision. However, CMR systems are not a panacea and need to be fit for purpose. Our informatics perspective on this case is to call for widespread use of CMR systems - designed to guide and protect.

Keywords: medical records systems, computerised, patients, medical errors, malpractice, risk, risk management 


\section{COMPUTERISED MEDICAL RECORDS TO SUPPORT CARE}

Lawrence Weed's perspective on medical errors is pertinent to the Bawa-Garba case. This case was one where Hadiza Bawa-Garba, an unsupervised junior doctor who was found guilty of mistakes in care and was removed from the UK medical register following the death of a 6 -year-old boy. ${ }^{1}$

Almost exactly 50 years ago, Lawrence Weed wrote his seminal articles on 'Medical Records that guide and teach'.2,3 Weed looked at the chaos of the medical record and reported:

"When I pick up a chart that is a bunch of scribbles, I say: 'That's not art. It certainly isn't science. Now, God knows what it is'." 4

And, his view of how we as a medical professional try to analyse patients' problems:

'An epidemic of errors and waste is occurring as we persist in trying to do the impossible'. ${ }^{5}$

Weed saw an intractable problem in medicine - the unrealistic expectation, that one's brain, no matter how well-trained, can store all the information required to make a proper decision. ${ }^{6}$

His solution was to look to organise medical records around problems - he invented the problem-oriented medical record (POMR); computerise these records; and link knowledge bases to these records.

\section{COMPUTERISED MEDICAL RECORD SYSTEMS TO SUPPORT SAFE PRESCRIBING?}

One of the errors in the Bawa-Garba case was the administration of a blood pressure-lowering drug by a nurse. We might anticipate that a computerised medical record (CMR) system might have questioned or blocked that prescription. There is some evidence from systematic reviews that computerised prescribing - often referred to in USA as computerised physician order entry (CPOE), might make a difference:
'Clearly reduces medication prescription errors; however, clinical benefit of CPOE systems in paediatric or ICU settings has not yet been demonstrated'. ${ }^{7}$

'Studies of computerised provider order entry with clinical decision support compared with the studies without clinical decision support reported a $36 \%-87 \%$ reduction in prescribing errors' 8

'The transition from paper-based ordering to commercial CPOE systems in ICUs was associated with an $85 \%$ reduction in medication prescribing error rates and a $12 \%$ reduction in ICU mortality rates' ${ }^{9}$

\section{INCLUDING SUPERVISION ARRANGEMENTS IN CMRs}

Compared with the complexity of prescribing, it should be relatively simple to incorporate into junior and senior doctors' rotas information about who is supervising or supervised by whom. However, as far as I can see this is not a part of the current initiatives around rostering software (e.g. https://www.drsusers.nhs.uk/). Such applications could inform hospital medical directors and executives if there are any, or list of the number of trainees without supervision live via a dashboard or other media.

\section{USING ROBUST CMR SYSTEMS}

Part of the narrative of the Bawa-Garba case, is that an incorrect decision was made about whether to continue with resuscitation. We are not clear whether information about this was recorded on physical paper records or CMR system or a combination of both. It should be possible to specify that CMR systems readily make available this information.

With a fully-fledged and fail-safe CMR system been used, it is possible that it might have impacted on the outcome of this case. Weed suggested elements of a computerised POMR system (Figure 1) that might have impacted on this case and supported better decision making.

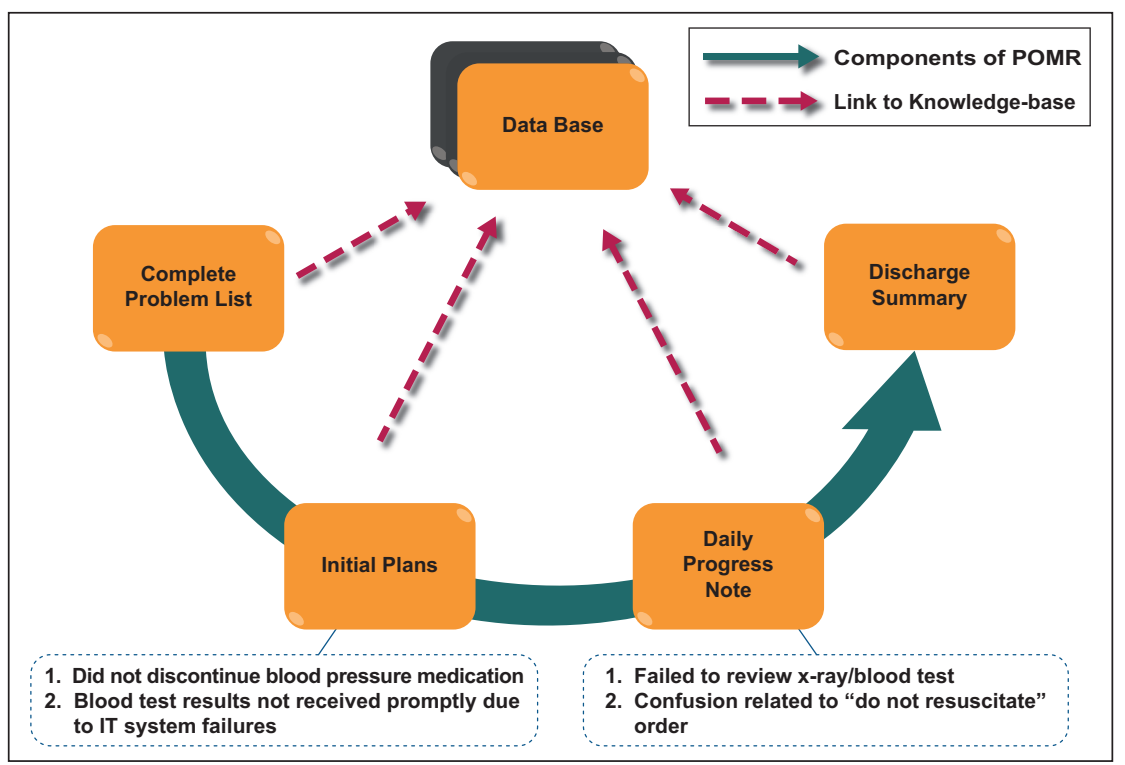

Figure 1 Function of a POMR system that might have impacted on elements of the Bawa-Garba case 
ETHICAL CONSIDERATIONS FOR CMR SYSTEMS

Another aspect of this case was a 4-hour delay in receiving a test result due to an information technology (IT) failure. Downtime is a recognised ethical issue in health $\mathrm{IT}^{10}$ and exposes the fact that there is a broader range of ethical concerns raised by both CMR use and non-use. These considerations include dimensions such as perceived workload impact, ${ }^{11}$ usability ${ }^{12}$ and commercial barriers to quality regulation of CMR systems. ${ }^{13,14}$

\section{CALL TO ACTION FOR THE HEALTH AND CARE INFORMATICS COMMUNITY}

Weed flagged half a century ago that we are asking doctors to process more information that one person can possibly do

\section{REFERENCES}

1. Dyer C. Doctor convicted of manslaughter is suspended from register for a year. BMJ 2017;357:j2928. doi: 10.1136/bmj.j2928.

2. Weed LL. Medical records that guide and teach. New England Journal Medicine 1968;278(11):593-600.

3. Weed LL. Medical records that guide and teach. New England Journal Medicine 1968;278(12):652-7.

4. Wright A, Sittig DF, McGowan J, Ash JS and Weed LL. Bringing science to medicine: an interview with Larry Weed, inventor of the problem-oriented medical record. Journal of the American Medical Informatics Association 2014;21(6):964-8. doi: 10.1136/amiajnl-2014-002776.

5. Jacobs L. Interview with Lawrence Weed, MD- The Father of the Problem-Oriented Medical Record Looks Ahead. The Permanente Journal 2009;13(3):84-9.

6. Grimes W. Dr. Lawrence Weed, Pioneer in Recording Patient Data, Dies at 93. NY: New York Times, 2017. Available from: https://www.nytimes.com/2017/06/21/science/obituary-lawrence-weed-dead-patient-information.html.

7. van Rosse F, Maat B, Rademaker CM, van Vught AJ, Egberts $\mathrm{AC}$ and Bollen CW. The effect of computerized physician order entry on medication prescription errors and clinical outcome in pediatric and intensive care: a systematic review. Pediatrics 2009;123(4):1184-90. doi: 10.1542/peds.2008-1494.

8. Rinke ML, Bundy DG, Velasquez CA, Rao S, Zerhouni Y, Lobner $\mathrm{K}$, et al. Interventions to reduce pediatric medication errors: a systematic review. Pediatrics 2014;134(2):338-60. doi: 10.1542/peds.2013-3531.

9. Prgomet M, Li L, Niazkhani Z, Georgiou A and Westbrook JI. Impact of commercial computerized provider order entry (CPOE) and clinical decision support systems (CDSSs) on and that CMRs systems were the way to improve quality. Our discipline should be arguing more strongly for the introduction of systems that might reduce errors and leave managers and executives in our systems aware of the load placed upon junior staff.

Whilst far from perfect, ${ }^{15}$ such systems might prevent and if not help us to learn from cases such as this to reduce the chance that it may happen again.

An important priority for health services should be ensuring that patient data are held on CMR systems that guide and protect - the patient as well as their doctor and nurse.

medication errors, length of stay, and mortality in intensive care units: a systematic review and meta-analysis. Journal of the American Medical Informatics Association 2017;24(2):413-22. doi: 10.1093/jamia/ocw145.

10. Mercuri JJ. The ethics of electronic health records clinical correlations [Internet]. Clinicalcorrelations.org. 2018. Available from: http://www.clinicalcorrelations.org/?p=2211. Accessed 13 March 2018.

11. Read-Brown S, Hribar MR, Reznick LG, Lombardi LH, Parikh $\mathrm{M}$, Chamberlain WD, et al. Time requirements for electronic health record use in an academic ophthalmology center. JAMA Ophthalmology 2017;135(11):1250-7.

12. Middleton B, Bloomrosen M, Dente MA, Hashmat B, Koppel R, Overhage JM, et al. Enhancing patient safety and quality of care by improving the usability of electronic health record systems: recommendations from AMIA. Journal of the American Medical Informatics Association 2013;20(e1):e2-8. doi: 10.1136/ amiajnl-2012-001458.

13. Koppel R. The health information technology safety framework: building great structures on vast voids. BMJ Quality and Safe 2016;25(4):218-20. doi: 10.1136/bmjqs-2015-004746.

14. Goodman KW, Berner ES, Dente MA, Kaplan B, Koppel R, Rucker D, et al. Challenges in ethics, safety, best practices, and oversight regarding HIT vendors, their customers, and patients: a report of an AMIA special task force. Journal of the American Medical Informatics Association 2011;18(1):77-81. doi: 10.1136/jamia.2010.008946.

15. Thomas $\mathrm{M}$ and Thimbleby $\mathrm{H}$. Computer bugs in hospitals: an unnoticed killer. 2018. Available from: http://www.harold.thimbleby.net/cv/files/killer.pdf. Accessed 20 March 2018. 